\title{
James Wetherbe: How Consulting Connects Colleges to the Real World
}

\author{
Jon Eckhardt (University of Wisconsin-Madison)
}

KEYWORDS: Information, Software, Data, Entrepreneurship, Innovation, Research Methods.

James Wetherbe is the Richard Schulze Distinguished Professor at the Rawls College of Business at Texas Tech University. Previously he served on the faculty and the University of Houston, Minnesota and Memphis. Rated as one of the top 12 consultants and lecturers on MIS by Information Week, also ranked as one of the 20 most influential scholars in the field. Corecipient of the first MIS Quarterly Distinguished Scholar Award, author or co-author of 35 books (including multiple editions) and widely published in top journals with over 13,000 citations. Professor Wetherbe brought in over \$15 million in funded research during academic career. He served on the Board of several major corporations including Best Buy and CIBER. Wetherbe was an early proponent of using science and technology to solve business problems and to help managers and companies make better decisions. A founding editor of the Entrepreneur \& Innovation Exchange, Wetherbe is also a trendsetter in using online platforms to improve academic publishing and bring new research and insights to other academics and practicing entrepreneurs more quickly.

\section{In recent years Wetherbe has been an outspoken opponent of academic tenure (https://eiexchange.com/content/102-entrepreneurs-do nt-get-tenure-should-their- \\ profe?search=time\%20for\%20tenure), which he has turned down four times because he believes it breeds complacency, causes professors to focus on research that yields little value, and undermines the teaching process(https://hbr.org/2013/03/its-time-for-tenure-to- lose-te) .}

This discussion with Wetherbe by EIX editor Jon Eckhardt, Professor at the University of Wisconsin, continues a theme explored with Professor David Teece of the University of California - Berkeley: how academics can make their research more meaningful and useful by engaging with businesses and their real- world problems. This is called translational science in some disciplines, and it's very common in the medical world where many physicians both practice medicine and research how to extend and improve human life. Wetherbe was one of its early pioneers in the business world, and in this edited interview he shares his history and his thoughts on how both academics and colleges can use this model to do research that really matters and to serve students better in the process.

\section{An Early Exposure to Technology Jon Eckhardt}

Jim, why did you decide to become a professor?

\section{Jim Wetherbe}

It first occurred to me when I was an undergraduate in class and I just saw the value of being able to learn from somebody. I thought it was such an honorable profession to be in a position to allow people to learn things that would help them in life and in their career. That made a lasting impression on me.

\section{Jon}

And how did you decide which field you were going to specialize in?

\begin{abstract}
Jim
Well I was living in New Mexico; my father was a scientist working with computers. He was a computer scientist and physicist so I became exposed to computers early on. A lot of technology was happening in New Mexico during that time related to the space program and military weapons. The first atomic bomb was tested near where I went to high school. Anyway, I got a chance to work at a Holloman Air Force Base and White Sands missile range and get exposed to scientific computing. But I needed a way to work my way through school, and so that allowed me to get a job in the university computer center. Not too many people my
\end{abstract}


age can say their old man was in the computer business, because he got in back in the time when they projected the total number of computers that would ever be made would be 10 ! Obviously that changed rather dramatically from then.

I was just very fortunate to just be in a part of the country where there was a lot of computing going on, where they were doing all this scientific research with the space and defense programs.

So that's how I got into it. It helped me get a job on campus and I really enjoyed working with computers and my attraction was to business. I had some jobs working in retail and I found a lot of excitement in just satisfying customers. Over time I just saw how technology could play a real role in enhancing the customer experience and prove the competitiveness of a business. I migrated from a scientific approach to computing to a business approach and worked my way through school in the university computer center. Of course, there I was working on registration systems and financial systems for the university and just developed from there.

Then, when I got my business degree, I thought for sure I would want to get a PhD in business and information technology, but I didn't want to paint myself into a corner. I'd learned that every time that you make a decision you're increasing some options and you're decreasing other options, and had I gone directly for a PhD I would have had more difficulty getting into business as a business person.

The people that I met at that stage in my career who really impressed me had worked for computer vendors such as IBM or CDC or some of the other main computer companies at the time. They either worked for them currently or had worked for them. So my strategy was to get my degree and go to work for a computer vendor for two or three years and if I liked it that's where I would stay, but if I still had that desire to be a professor I would be that much better suited to be a relevant professor.

\section{Adding a Business Perspective Jon}

When did you first integrate your research experience with a business or applied experience? Was it during your PhD or after that?

\section{Jim}

Well my perspective evolved. I worked in the university computer center and I found working with the technology actually gave me an advantage over other faculty. I was always concerned about just being a professor. I worried that if I wasn't hands-on that I would not be current or relevant. So my original strategy was to be a director of a computer center and continue to work with the technology and then also be a professor -- a joint appointment.

A few things would change that. When I went to work in the computer industry l acquired some fabulous training. I worked for NCR in their computer division. In business schools you learn finance, marketing and accounting, the functional areas. But if you're going to work for a company that is marketing and technically supporting computers, you also must learn banking, retailing, wholesale distribution, hospitals, medical industry, etc. I went from the functional to horizontal in a hurry. I found that I really loved all these different types of businesses that I really didn't get exposure to in the business school.

So that was one defining experience. After that point I thought I had to work with the technology to be current, but I was learning how important it was to work within different industries such as banking and retailing and manufacturing. So that really changed my perspective at that point.

There was another defining moment. I still thought I wanted to run the university computer center and then be a professor, but I went to a conference in Chicago and I met two people who really changed my worldview on this, and one was Dick Nolan and the other was Warren McFarlan, both from Harvard. They were just so insightful about technology and how to use it, and basically the whole purpose of the technology is to allow an organization to make better decisions and operate better. You can also help reduce cost while helping them to perform better; so it's a compelling value proposition to be involved with this field.

I saw that these thought leaders were doing something that was different. I had worked for a computer manufacturer so I had my customers, but I was limited by the technology and the product that I had to sell. Sometimes I had the best product and sometimes I didn't. Nolan and McFarland did not have those constraints. They were in the idea business. They were 
thought leaders, and they were doing it by engaging with lots of different companies in different industries, which was what I had been doing, but they were advancing were ideas and ways to do things, methodologies. They could select from any technology they wanted.

What allowed them achieve this was they were first obviously very talented, but they also had access to major metropolitan areas. Up to that point I had never really made the distinction between being a college town professor or being an urban campus professor. I realized that if you wanted to have ready access to companies and engage with them on a convenient and regular basis, an urban campus would give you an advantage.

And so my strategy changed to becoming a full-time professor in a major metropolitan area where I could engage with businesses and do what Nolan and McFarland were doing. And for a professor it's a great gift, because you're given a day a week to do outside activity, which you're encouraged to do, so you can engage in consulting work, and that's how I could keep my hands-on experience that would be important to be a high quality researcher and teacher.

\section{Jon}

You said early on that when you were director the university computer center while you were also doing your PhD, you felt that it gave you insights or advantages that were not available to faculty who were not engaged in practice. Can you elaborate on what advantages you got or insights you had because you were trying to build these systems and use them?

\begin{abstract}
Jim
I was helping faculty with research and technology, and students who were trying to learn how to use the technology. I was also working on university administrative systems, such as developing an online registration system. I had hands-on experience so that when I talked I could speak to experience and I found that to be very useful. That was the dynamic. It was not just the administrative systems, it was also working with people trying to do research and use computers to help them do research.
\end{abstract}

\section{Jon}

Did these experiences help you see opportunities for scholarship that the professors were not seeing because they weren't involved in trying to build those systems?

\section{Jim}

Correct, I could help them do something that they could not otherwise do using the latest technology correctly.

\section{How Professors Can Double their Income and Give Back Jon}

You have mentioned that many professorships allow faculty to have a day a week where they can be involved in outside consulting activities. Can you talk more about that?

\section{Jim}

That is probably one of the most underutilized gifts, because if you think of it, you could be writing a book, doing consulting work, and other things that supplement your income and professional growth. I didn't take a vow of poverty to become a professor. It's not the highest paying occupation, but there are other ways that you can supplement your income very meaningfully while growing professionally. In fact, early in my career I learned this algorithm: you should be able to at least double your income on the outside. That became my goal. It's a very realistic goal for any professor. This additional income over the years has supported "givingback" philanthropic initiatives including endowing a couple of professorships, scholarships, excellence funds, classrooms and a chapel.

\section{Jon}

It must be wonderful to be in a position to become a philanthropic professor. Did you ever spend more than a day a week on the outside? Did you dial back your faculty appointment? Some people we've talked to have taken that approach.

\begin{abstract}
Jim
Yes, in fact I did. And here are some principles that I found to be very useful. One, there is no substitute for doing research and advancing knowledge if you're going to consider yourself a scholar at a prestigious research university. So you can't say, I'm a really good book writer so I don't do original research. That doesn't count.
\end{abstract}

Secondly, there is absolutely no excuse for not providing a good learning experience for students. In other words, 
you have to be a good teacher. Third, there is no reason to not do whatever else you find to be very exciting in your work. For me it was consulting and speeches. One of the principles of my consulting was I never engaged in consulting if I didn't see the opportunity to find a problem that needed to be solved, or a leading edge issue that someone is trying to address, that academic research might be able to help. That day a week is what allows you to be engaged in that type of activity and it also supplements your income. We lose too many talented professors to industry because university salaries are not competitive. Consulting is a way to resolve that.

\section{Jon}

You said there were sometimes when you went beyond a day a week, can you talk about those situations?

\section{Jim}

Well, consulting, especially if your clients are pleased, can quickly lead to seminars, speeches and keynote addresses, all of which take much more time than one day a week. At one point in the mid-point of my career I was doing 150 speeches a year internationally. If you become a thought leader in a field - and I was blessed to become one of the top 12 thought leaders in the field - corporations wanted to engage with you often as a keynote speaker. I didn't ask the university for travel and I was getting paid what I quite frankly considered to be obscene honorariums for these appearances, in contrast to academic conferences that rarely pay honorariums or travel expenses. As demand for paid engagements increased, I negotiated with the university to reduce my appointment from full-time to part-time so that there would never be a question as to whether or not I was fulfilling my university responsibilities and or abusing the one day a week policy.

\section{FedEx and Best Buy \\ Jon}

There are two specific projects I would like to ask you to discuss so we can acquire a better understanding of the link between your research and your consulting activities and your ability to improve practice. One was a project with FedEx and another was with Best Buy. Can you talk us through the work you were doing for FedEx and how that led to some research as well?

\section{Jim}

Sure, when you're a professor there are questions that need to be answered and problems that need to be solved and you have the freedom to pursue the ones you find the most interesting via research. When you're engaged in speeches or seminars or consulting you continually become aware of new questions and problems.

I was approached about being the FedEx Professor of Excellence at the University of Memphis while I was still at the University of Minnesota. They were just going to offer me a nice \$3 million endowed chair, but I didn't want to just sit over there on campus and be a FedEx professor. I wanted to have a meaningful working relationship with FedEx. And so after I was offered the position I said thank you, but now I need to meet with (FedEx CEO) Fred Smith to see if we can find a meaningful, mutually beneficial research agenda.

I'd studied FedEx, and a lot of people think that they are just in the package and shipping business, but they are really in the business of eliminating inventory. So before I would accept the chair, I wanted to make a proposal to Fred Smith and see if he was interested. And so I had a one-hour meeting during which I asked for a million dollar grant. We affectionately refer to it as the milliondollar-an-hour-conversation. I laid out some ideas on how we could use research and logistics and information technology. Fortunately Fred knew Sam Walton, who always said that everyone assumes Walmart is successful because of its big stores and its economy of scale, but it's really because it substituted information for inventory.

So I shared this whole concept of how we could really help FedEx and FedEx customers by offering a valueadded service that was research-based. This led to the FedEx Center for Cycle Time Research at the University of Memphis, which I ran for seven years. We published research that FedEx, in turn, could use to help their customers deal with logistics, cycle time and inventory reduction types of issues.

This is a real model of how research can be useful. Whenever I would do research I would always try and get it into a research journal, then try and get one or two practitioner pieces out of it. That's why I was always looking for consulting work that had an advancingknowledge research edge but would also then allow promotion of application of the work.

\section{Jon}


Tell me about how you used this approach at Best Buy, where you served on the Board of Directors.

\section{Jim}

As internet retailing began to emerge, Best Buy was concerned about how customers would decide to "click or brick" when purchasing. This was a compelling question that needed answers that could be achieved through research.

Best Buy funded several doctoral dissertations based on research into customer behavior and the Internet. The findings were published not only in top journals but also in more mainstream publications like Business Week. For one study we were trying to find out what attracted people to an internet shopping website and kept them there, and what caused them to abandon the internet shopping experience. We used a research methodology called protocol analysis. It works like this: people using the website would talk out loud and we'd record what they said and go back and reconstruct the cognitive processes they were going through so we could learn what people liked and didn't like about websites.

One of our big research findings: whenever online shoppers saw a shipping expense they would often just click off and go to the store. It wasn't rocket science, but it was an incredibly useful finding to get published in Business Week, and showed that if you want to sell online then free shipping is a really good strategy.

\section{Balancing Research and Business Jon}

From what we've discussed, it seems that to be successful as a translational scientist you have to excel both as a researcher and in business, and understand how research should be relevant to business. Essentially you have to have two skills and excel in two separate careers instead of just one. How did you yourself find ways to balance those two things? You did mention that you dialed down your professorship for a while, but in general how did you manage the balance and intentions between these two different worlds?

\section{Jim}

Great question. First of all I don't think my way is the only way. It's a great model for faculty members who like business and enjoy interacting with business people. But these professors still have to do research that gets published in academic journals. I've seen some professors get so caught up in the consulting and seminars and speeches that they neglect this. If you do that you're basically ending your academic career. There is no substitute for doing academic research where you're advancing the field.

I would be given a lot of very lucrative consulting opportunities, but I would be just repeating activity I had done before and I didn't see it as advancing my skill set, my knowledge, or my ability to advance any thought leadership. I would turn those down. You can't just make economic decisions. You have to make the decisions based upon is this something that helps you grow intellectually as a thought leader.

Another criteria for accepting consulting work was whether the client would let me collect some data during the work and publish the results. With knowledge of research methodologies and field research, a routine consulting process could easily turn into a field research project. That just had to always be on the radar screen in terms of anything that I would accept.

Now some academics are purely academic and just want to advance knowledge for the sake of discovery but it may lead to application. As an example, a relational database is a very important aspect of organizing data in the field of information systems. It evolved from relational calculus, a purely academic subject that didn't interest me until I saw its connection to organizing data, a real world problem. Many universities struggle to balance the academic with the practical, and they have to find the connection between them.

Minnesota, where I spent 20 years, has always been regarded as one of the top MIS programs, and that's because of the leadership of Gordon Davis, who was a key founder of that program. Gordon understood the concept of a portfolio of faculty: of having both people who can do a great job in the classroom and people who can give keynote speeches and be ambassadors for the university and its work. I once asked the President at the University of Memphis if he minded that I worked part-time and was gone most of the time, and he told me I couldn't build a reputation for the University of Memphis or FedEx if I'm just hanging around Memphis.

But if everybody spent time away from campus, you wouldn't have the stability on campus that you need. You also need a more traditional campus-type professor 
-- people who are willing to do teaching and/or academic research just for the sake of advancing knowledge. If research becomes too applicational the college starts to look like a consulting company, and academic relevancy and value become a challenge.

\section{Jon}

What would be the problems or drawbacks of a business school that went too far on the consulting side?

\section{Jim}

I think the problem is there could be a distraction for original, exploratory academic research and teaching. There would be the potential for more and more people wanting to be more and more part-time, and fewer people to teach classes. There was a time there when I wasn't teaching classes because I was traveling extensively.

At this stage of my career, I came back to my alma mater to give back, and it's a college town, Texas Tech, and I'm teaching more classes than I ever did. I'm enjoying it, and don't miss the travel, but there was a time where that was what I did and it was a very exciting time and part of my career. But if everybody is doing that, you don't have enough stability on campus for people to mentor students and hang out with students and do things that are also very important.

\section{Playing Matchmaker Jon}

How did you help other faculty who were maybe less involved in outside activities to accept and appreciate the work that you were doing on the outside?

\section{Jim}

I ran the MIS research center for 20 years at the University of Minnesota, and one of the things that I would do is play matchmaker between my corporate sponsors and the faculty members and students who might be able to do research that helped corporations with problems and questions. For example, there was a time when $3 \mathrm{M}$ was funding research when color graphics were first coming out. The questions became: do they help presentations? We did a couple of doctoral dissertations with faculty who were working in that space to determine what impact it had on the audience: if high-quality graphics are part of a presentation, was it more persuasive?
So there were lot of problems and questions that I could uncover, but I couldn't have the bandwidth to do them all myself. So, I would parcel out research possibilities among junior faculty and doctoral students, and that way they could be funded. Here is a real crime, if you were going to pay me to solve a business problem today I would charge you $\$ 250,000$ for work that was equivalent to doing a dissertation. But we have people doing that much work just to get a PhD degree, and sometimes they work years on a dissertation that has no real usefulness once it's done. All they did was demonstrate that someone is methodologically capable of doing quality research, but the research question or problem wasn't that interesting or useful to anybody.

To me the ultimate hit for someone who is doing my business model of being a professor was to get a doctoral dissertation funded. So if I could get a dissertation funded for $\$ 50,000-75,000$ to support relevant research that was a true win/win. A faculty member who is engaged in the business world can be a matchmaker and help someone who doesn't really have the skills to go find someone who would sponsor their research.

\section{Jon}

After a distinguished career in academia and consulting, what is your priority now?

\section{Jim}

EIX (https://eiexchange.com/) is a brand new journal that is social media-based, and I helped to launch it with funding from the Richard M. Schulze Family Foundation (https://www.schulzefamilyfoundation.org/) . We started it to address the main problem with academic publishing: paper journals are archaic, they take too long to publish, 3-4 years, and you can't easily share the information or correct or update it if it's wrong. Nor can you provide hot links to references.

The print journal is an inferior product. I can show this new journal, EIX.org, to a group of students and show them a print journal and it's so obvious to them. Innovation goes through three stages: joke, denial, and obvious. Early on colleagues said print journals are where the prestige is and considered online journals a joke and denied they would ever replace print journals. Anyone who has interacted with EIX vs. print journal, there is just no comparison. Over a half million readers access EIX annually. 


\section{Jon}

What do you see as the future of translational scholarship in business schools? Do you think it's becoming more significant?

\section{Jim}

It's going to have to become more significant and here's why. The medical school paradigm is a good way to consider it. They do lots of funded research and they don't want medical professors teaching that are not practicing. They can't practice medicine and do meaningful research. What we do right now I think is a scam. We give faculty release time from teaching to do research that's not funded and would not be funded by business. So who is paying for that research? It's paid for by taxpayers, if you're a public university. It's paid for by tuition that would otherwise be paid for teaching; people are being paid to do research without market place scrutiny.

The statistics again are appalling. $50 \%$ of articles that are published in academic journals are never cited, so we're paying for something that has questionable economic value. The marketplace doesn't lie to you. If you say I think this is important, a good way to prove it's important is to find somebody who is willing to fund it. That funding then can be used to pay the professor to do that on a reduced teaching load -- as opposed to giving them release time, which is an economic burden to the college, the taxpayers and the students who are paying tuition.

We've got to do something to improve the economics of education, we've got to do things to improve the relevance of it, and I think translational research is absolutely key. Outside funding for research can not only make research more relevant, but also help underwrite other costs that would be taken from other programs or passed on to students or taxpayers. For example, under the terms of our agreement, FedEx would give me the research money and $75 \%$ of it would go directly to cover the cost of the research and $25 \%$ for other purposes that FedEx might not see as a necessary value. But if you think about what a company does, a company takes the money needed to do research from its profits. Without an R\&D function a company is going to die.

\section{Jon}

It sounds like a well designed translational research enterprise can also be used to fund very basic science questions with little known link to practice that business schools may rightly value as part of a research enterprise that is pushing the frontiers of knowledge.

\section{Jim}

I think the economics of education are changing. Colleges can't afford to give a faculty member $\$ 25,000$ or $\$ 50,000$ to spend a summer researching just to publish in a journal. That is where I think translational research comes in. It has the value of keeping us relevant, the value of covering the cost of research. But you can overdo it; you don't want all your research to be dictated by corporations. So you need to have some freedom to use some of those funds for pure academic discovery.

\section{Read More on This Topic}

An Interview with David Teece, a Practicing Business Intellectual(https://eiexchange.com/content/349-an-inter view-with-david-teece-a-practicing-business-

intellectual?search=Teece)

Connecting Business Research to Practice (https://eiexchange.com/content/126-connecting-busine ss-research-to-practice?search=connecting\%20busines s\%20research) 